\title{
Concept of Design Activity Supporting Tool in the Design and Development Process of CPS
}

\author{
Jerzy POKOJSKI ${ }^{\mathrm{a}}$ and Lech KNAP ${ }^{\mathrm{b}, 1}$ and Michał TROJGO ${ }^{\mathrm{b}}$ \\ anstitute of Machine Design Fundamentals, Warsaw University of Technology \\ ${ }^{\mathrm{b}}$ Institute of Vehicles, Warsaw University of Technology
}

\begin{abstract}
Cyber-Physical Systems (CPS) are systems that link cyberspace with the physical world by means of a network of interrelated elements (sensors and actuators) and computational engines. These different assets make it difficult to design properly and effectively with them all. Additionally, the designing of CPS requires multi-disciplinary project teams and the investigation of all activities which CPS should perform. The cooperation of specialists in only one area is often difficult. One can easily imagine what problems arise when designers from totally different fields have to cooperate. The designers have to share their knowledge and experiences, and to identify assets and activities which are necessary for the proper CPS functioning. Attention has to be paid not only to the process itself, product models, requirements and constraints, aspects of analysis and synthesis, automation tools, and the wider contexts of particular issues but also to the identification of design activities (performed by human designers) and requirements related to them. The proper identification process of the CPS activities allows to improve the design process through more precise and problem-activity-dedicated knowledge and activity-design models management.
\end{abstract}

Keywords. CPS, knowledge modeling, assisting systems in engineering

\section{Introduction}

Designing of CPS-class systems and designing of machines with CPS elements is a relatively new area of research. Although many works can be found in the literature related to this subject (e.g. [1-8]), majority of them concern the perspective narrowed down to a specific class of cases or solutions (e.g. $[1,5,8]$ ). Relatively few of them propose more general and universal approaches [2-4]. Also, some of them concentrate on the requirement that methodologies for CPS-design should be part of a multidisciplinary development process within which designers would focus not only on the separate physical and computational components, but also on their integration and interaction [7]. Other authors, in the process of designing the CPS, focus on how to model and design the joint dynamics of software, networks, and physical processes [5], [8]. Inherited problem of safety connected with the use of the CPSs have also been in last few years subject to intensive research [9], [10] but still formal and recent regulations other than [11] are missing.

\footnotetext{
${ }^{1}$ Corresponding Author, Mail: lech.knap@pw.edu.pl.
} 
The authors of this paper worked on developing a functional industrial project, the aim of which was to design a specific technical system with CPS elements - a tractor electronic transmission control unit (TCU). The project was started using classical design methods but in the course of the project the authors observed that this approach in multidiscipline environment was not sufficiently productive and thus a process-oriented approach was applied [12]. One of the final conclusions was also the suggestion that the whole process needs to be improved by creating a concept and then building a dedicated environment supporting this class of tasks in the following areas: informal and formal knowledge consolidation/storage/management [13], creation and simulation/analysis of CPS models [1, 2], supporting decision-making processes in design using the multidisciplinary design approach applied in selective way [14, 15].

The goal of the work carried out over a longer period was to create the concept of assisting software for designers. This software strives to support the design process of a product treated as a CPS $[13,16]$. It was assumed that an assisting system allows design knowledge management at both the elementary level and at the level of entire classes of typical knowledge elements, or classes of elements requiring certain adaptive actions offering moving away from stereotype design solutions [17-22].

One of the basic elements of the assisting system is the concept of modelling project activity for projects with CPS components. This work is an attempt to create such a concept primarily based on information and knowledge from the real-life project.

\section{Design activity modelling}

\subsection{Real-life project inspirations}

The authors decided to consider, analyze and structure the design process by identifying and isolating individual design activities of the CPS system's real-life design task [13]: the design process of the electronic system (TCU) that controls the transmission and other selected tractor systems. The information, knowledge, that has arisen or has been accumulated as a result of the project implementation and the integrated documentation, was used as material for building the concept of individual components of the assistance software - including the conception of the project design activity which is the basic idea for the proposed approach [23-25].

The TCU project was developed by a team of designers - specialists from various disciplines, with a broad professional experience. Most of those designers had relatively rich professional biographies, and they had also a long-time experience in the team project work (9 - designers from 3 companies).

The main novelty in the project was the problem of specifying the scenarios for the functioning of a newly designed CPS device, both in an informal way - specifying the situations in which the structure should function, as well as formally modeling these situations to the extent that allows advanced analysis and design simulations.

In their analyses, the authors of the paper used project documentation and various additional information resources created during the TCU project implementation. One of the authors was also the member of the design team.

The designers, team members with large experience in specific design processes or some of their fragments referred most often to their projects using terms of design activities. Design activities can be associated with various groups of issues in the design 
processes which have usually arisen from issues encountered during designing or testing scenarios of CPS.

\subsection{Details of initial design activity model}

For modeling of the design activities, the authors of this paper use a classic approach from work [23]. The first stage of the analysis was to identify the design activities used by individual designers in their own original version. The original version was considered, i.e. the one with which the designers started to solve the problems. The result of this stage was the separation of three classes of activities:

1. such that did not require any modification in the case of the currently implemented project task,

2. those that required relatively simple modifications that could be made already at the stage of the first design iteration,

3. those that required far-reaching, unknown at the beginning, modification of all activity.

After analyzing the process of such selection, it was noticed that the activities belonging to class 3 ) generally resulted from the need to design CPS elements or to solve the encountered unforeseen issues. Their current form did not allow to solve the actual design problems. Usually, the goal of the activity was set and some new ideas (based on continuously improved input/output knowledge from previous version of activities) appeared to solve further newly identified problems.

The designers very often began to create one or several versions of the solution to the problem, experimented, drew conclusions and made improvements. They created new versions of those activities, tried to apply them to a given design problem. Sometimes an extensive research material was needed.

\subsection{Results of initial design activity model application}

Changes made to class 3) activities required repeated design analyses to be carried out as a whole process. This, in turn, could lead to the appearance of new modifications in the types of activities 2) and 3).

During the implementation of the design process, the gradual evolution of the form of considered scenarios for the functioning of CPSs, as well as adding new scenarios to the set originally assumed, was an additional element significantly broadening the scope of the entire design process. To a large extent, this was due to the new opportunities that arose as a result of project activities in subsequent iterations of the project (in the beginning, the semi-automatic gearbox TCU evolved into the concept of the semiautomatic/automatic gearbox TCU with on-line diagnosing and monitoring possibilities).

All activities were based on the knowledge of designers, which has significantly evolved in the design process. Their formal record was based on the concept of text and multimedia descriptions or on tools that automate these activities. The proposed approach assumed that the project activity may relate to a specific substantive issue. It can be modeled as a descriptive and multimedia resource [26, 27] functioning at three levels of accuracy (1-3, 3 most accurate) and can be modeled as an automation tool [28, 29 ] also at three levels of accuracy (1-3, 3 most accurate). 


\subsection{Concept of design activity template}

Trying to build a more structured shape of the whole approach, the authors created the concept of a template related to activity (concept taken from [26, 23]), which may include both descriptive and multimedia components as well as automation components corresponding to the typology of [23].

Designing of CPS is usually multidisciplinary (in reality, in most cases these models are transdisciplinary) $[14,15]$, leading to the need to integrate many formal models with each other.

The following chapters present exemplary, detailed results obtained in individual groups of issues: analysis of implemented activities, modeling of activities evolution.

\section{Analysis of performed activities}

As part of the work, a number of activities was performed, which included familiarizing with the resources of knowledge used in the considered project task, classifying this knowledge, tracing both its sources and processes of its evolution in relation to the solved project tasks, mainly related to work scenarios of CPS. The listed knowledge resources, experiences and processes based on this knowledge and experience are schematically presented in figure 1. Both personal resources and team resources are visible. Knowledge evolution processes resulting from emerging tasks are presented. The entire resources of knowledge used are schematically marked at the top of the figure. The bottom part of the drawing presents scenarios for the functioning of the designed CPS in connection with the designers and their possessed and developing knowledge.

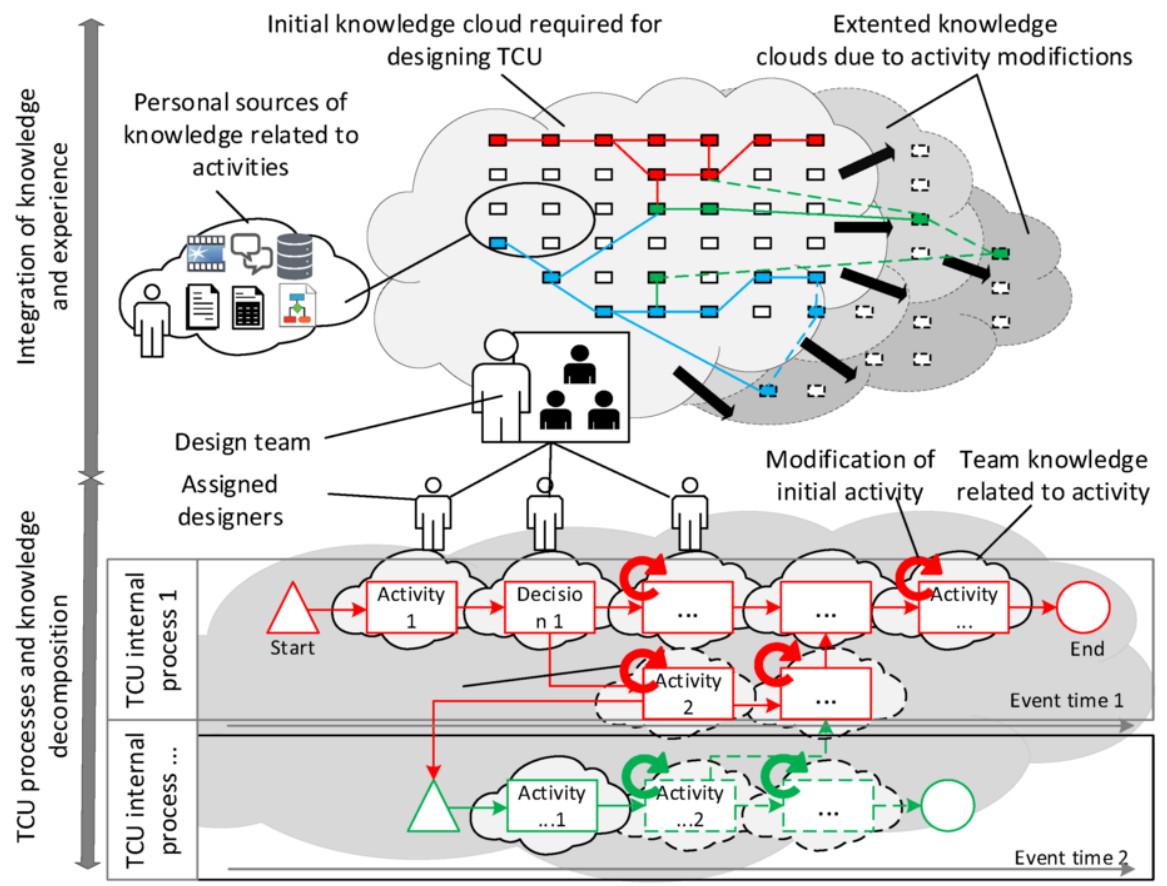

Figure 1. Schematic model of personal and team knowledge resources of designers in connection with implemented tasks - analysis of selected design scenarios. 


\subsection{Modeling, evolution of exemplary activity}

The paper analyzes in detail the individual activities which were extracted from the project records and the reports. The following concept of their structuring and analyzing was used:

1. All members of the designing team were identified and their substantive profiles, professional experience, etc. were specified. This summary in a simplified form is presented in Table 1.

Table 1. List of chosen team members and their characteristics.

\begin{tabular}{lllll}
\hline No & Team member & Area of specialty & $\begin{array}{l}\text { Experience } \\
\text { period } \\
\text { (years) }\end{array}$ & $\begin{array}{l}\text { Participation } \\
\text { in activities } \\
\text { (\%) }\end{array}$ \\
\hline 1 & $\begin{array}{l}\text { Mechanical } \\
\text { engineer No } 2\end{array}$ & $\begin{array}{l}\text { Hydraulic systems, numerical simulations, } \\
\text { tractor transmission and drivetrain, .. }\end{array}$ & 18 & 15 \\
\hline 3 & $\begin{array}{l}\text { External } \\
\text { mechanics and } \\
\text { hydraulics expert }\end{array}$ & $\begin{array}{l}\text { Tractor kinematics, optimization of gear } \\
\text { change process, hydraulic systems, ... }\end{array}$ & 28 & 5 \\
\hline 3 & $\begin{array}{l}\text { Electronics } \\
\text { engineer and } \\
\text { programmer }\end{array}$ & $\begin{array}{l}\text { Electronics architecture, programmer, utility } \\
\text { software development, ... }\end{array}$ & 15 & 10 \\
\hline
\end{tabular}

2. Design activities used by individual team members were identified and listed for each team member. An example of a set of activities for one designer is shown in Table 2.

Table 2. List of chosen activities and their characteristics - performed by one of the design team members.

\begin{tabular}{lllc}
\hline No & $\begin{array}{l}\text { Design project activities of } \\
\text { Mechanical engineer No 2 }\end{array}$ & Characteristic of tasks in activity & $\begin{array}{c}\text { (Group) Type } \\
\text { of modifications }\end{array}$ \\
\hline 1 & $\begin{array}{l}\text { Analysis of hydraulic system } \\
\text { supporting gear shifting }\end{array}$ & $\begin{array}{l}\text { Analysis and modeling of gear shift process } \\
\text { form hydraulic point of view }\end{array}$ & $\begin{array}{c}\text { (3) complex } \\
\text { modifications }\end{array}$ \\
\hline 2 & $\begin{array}{l}\text { Designing of gear shift } \\
\text { process and characteristic }\end{array}$ & TCU software tests & $\begin{array}{c}\text { (3) major } \\
\text { modifications }\end{array}$ \\
\hline 3 & $\begin{array}{l}\text { Testing of gear shift process } \\
\text { under the external load }\end{array}$ & $\begin{array}{l}\text { Measurement setup and tests of implemented } \\
\text { gear shift strategy (proportional valve } \\
\text { characteristics of disengaged and engaged gear) }\end{array}$ & $\begin{array}{c}\text { (3) major } \\
\text { modifications }\end{array}$ \\
\hline 4 & Model and data optimization & $\begin{array}{l}\text { Analysis and adjustment of control parameters in } \\
\text { TCU }\end{array}$ & $\begin{array}{c}\text { (3) complex } \\
\text { modifications }\end{array}$ \\
\hline
\end{tabular}

3. The activities and their elements were identified. For example, one of them is shown - with its structure - in Table 3.

Table 3. Analysis of hydraulic system supporting gear shifting activity and its structure.

\begin{tabular}{llll}
\hline No & Activity records & Form of representation & Format \\
\hline 1 & $\begin{array}{l}\text { Documentation of } \\
\text { previous projects of a } \\
\text { similar type }\end{array}$ & $\begin{array}{l}\text { Descriptive documentation, numerical } \\
\text { simulation model, measurement data, } \\
\text { experimental and numercal results, ... }\end{array}$ & $\begin{array}{l}\text { Files (doc, xls, pdf, ..), 2D and } \\
\text { 3D models, experimental and } \\
\text { simulation data, }\end{array}$ \\
\hline 2 & $\begin{array}{l}\text { Technical documentation } \\
\text { of the hydraulic system }\end{array}$ & $\begin{array}{l}\text { Descriptive documentation, } \\
\text { specifications, data sheets, ... }\end{array}$ & $\begin{array}{l}\text { Files (doc, pdf), 2D and 3D } \\
\text { models, graphics, pictures, ... }\end{array}$ \\
\hline
\end{tabular}




\begin{tabular}{llll}
\hline No & Activity records & Form of representation & Format \\
\hline 3 & $\begin{array}{l}\text { Additional requirements } \\
\text { from other activities, e.g. } \\
\text { design of electronic unit }\end{array}$ & $\begin{array}{l}\text { Descriptive documentations, required } \\
\text { functionalities, planned TCU } \\
\text { scenarios, risk report, .. }\end{array}$ & $\begin{array}{l}\text { Files (doc, pdf, xls, vsd, ..), } \\
\text { paper reports, graphical files, } \\
\text { pictures, video material, ... }\end{array}$ \\
\hline 4 & $\begin{array}{l}\text { Experimental and } \\
\text { numerical results and } \\
\text { data }\end{array}$ & $\begin{array}{l}\text { Experimental data, reports, video } \\
\text { material and pictures from } \\
\text { experimental investigation, ... }\end{array}$ & $\begin{array}{l}\text { Files (binary, mp4, doc, xls, } \\
\text { raw, jpg...) }\end{array}$ \\
\hline
\end{tabular}

4. Identified version of specific components of the analyzed activities. An example illustration of the versatility of the activity component is shown in Table 4.

Table 4. Exemplary metamorphose of activity analysis of hydraulic system supporting gear shifting.

\begin{tabular}{|c|c|c|}
\hline Activity & Version & Characteristics of additional problems solved or discovered \\
\hline $\begin{array}{l}\text { Analysis of } \\
\text { hydraulic } \\
\text { system } \\
\text { supporting gear } \\
\text { shifting }\end{array}$ & Initial & $\begin{array}{l}\text { At the beginning only hydraulic system, which was directly } \\
\text { supplying hydraulic pistons of clutch of proper gears, was analyzed. } \\
\text { Experimental investigations shown improper fluctuations of pressure } \\
\text { and the oil flow during shifting gears. This caused losing of clutches } \\
\text { for a while after initial engagement and later second immediate } \\
\text { engagement which caused overloading of transmission. }\end{array}$ \\
\hline
\end{tabular}

To solve malfunctions of gear shifting process it was necessary to investigate whole hydraulic system of tractor including pumps, pressure relief valves, proportional valves. It was discovered poor manufacturing of hydraulic plate which caused leaks during gear

Analysis of whole hydraulic system of the tractor
After major modifications shifting process. It was also necessary to introduce hydraulic accumulator to hydraulic system and adjust its volume and gas initial pressure. Although improvement in gear shift process was achieved still immediate engagement of clutch causing overloading was observed. It was discovered that, in spite of proper characteristic, control resolution of electronic components was to low causing too sharp increase in current supplying coil of proportional valves. It was necessary to include into analyzes measurements of electronic system and control signals.

After including into optimization parameters related to hydraulic, electric, mechanical and software parameters it was possible to determine proper control characteristics assuring proper process of gear shifting under different loads of transmission. But this also shown that was necessary to rebuild software algorithms to include possible corrections due to temperature (to compensate changes in oil viscosity) at the end of the production line during cold pickup. It

Analysis of all systems and software controlling gear shifting process
After further complex modification was also discovered that is possible to develop automatic valve characteristic adjustment software based on a few chosen measurements at the end of production line. Due to changes in this activity it was necessary to modify other activities related to designing of TCU. For. example it was necessary to adjust measuring system to measure signals from numerous different sensor (currents, torque, hydraulic pressure, oil flow, temperature, velocities of transmission shaft, engine velocity, engine torque, engine throttle, etc.) to enable analysis of measured values at the same time. 


\section{Design problem structure and evolving set of CPS functioning scenarios}

The collected and analyzed documentation of the designed CPS also includes the perspective of so-called scenarios of CPS functioning. During the process of designing the TCU it is necessary to determine the set of tasks required to be performed to provide the required functionalities. For instance, the following scenarios were identified and considered: Power Shuttle (drive control providing the gear shifting under load conditions), Power Shift (semiautomatic control with the system adapted to the automatic control system), accelerating and stopping the vehicle, control of the differential lock of the rear axle, connecting/disconnecting of the front drive, connecting/disconnecting of the PTO shaft, blocking of selected gears with the Creeper gear option on, managing the Brake \& Clutch function, etc. Based on identification of tasks, it is possible to develop scenarios to be performed by CPS. Proper identification of CPS scenarios allows for finding relation between the system components and transmitted information, such as electric signals. Each task in the scenario can be a source of multidisciplinary problems and risk which should be covered by the design process activities - cf. Table 4 .

\section{Functionalities of assisting software concerning activities}

\subsection{General model of activity}

As a part of the project, a model of design activity was defined, its general structure, existing forms and individual components. A predefined typology of recognized types of activities was prepared as well as related keyword sets. The built representation of the activity allows to capture its development in the form of subsequent versions - cf. Figure 2. This formalism is presented in chapter 2 of this work in the form of tables filled with content from a real-life design task.

The part of the model described above focuses primarily on the aspects of storing information/knowledge, preserving information about the relationships between individual elements. It can be implemented in the form of an object-oriented model.

The model under consideration and its functioning in specific situations refers very strongly to the mechanisms observed by W. B Arthur in position [30]. The point here is how technology changes over time, how it evolves.

\subsection{Modeling design activity development}

Project implementers have also created concepts and prototype solutions in the field of model functionality, whose task is to offer the rapid and effective development of the object-oriented activity model.

During the analysis of the material documenting the sample task, attention was drawn to the large number of activities that already existed at the time of project implementation but required modification made by the designers. Such modifications can be performed in a basic way by editing the object model and attaching it to the rest of the model.

The authors drew attention to the fact that system users - CPS designers, in this type of circumstances, usually work in two areas: 1) conducting problem-oriented, filtered analysis of the content of previously created data structures and knowledge, 2) creating 
and analyzing hypothetical extensions of already created data structures and knowledge. Users are usually interested in more effective solutions than manual analysis or extension of the existing object-oriented model [19, 29].

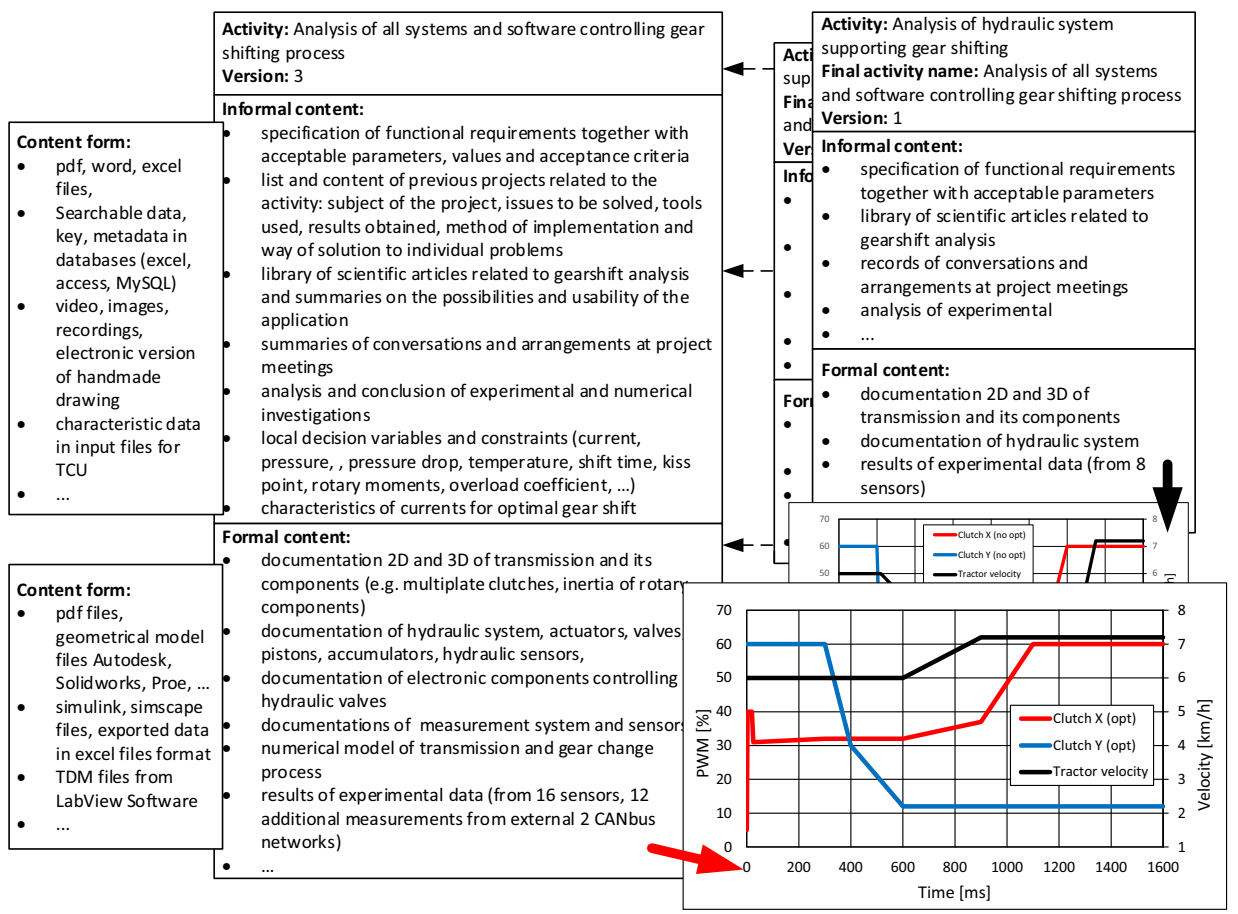

Figure 2. Schematic representation of the activity and description of its development.

\subsection{Problem-oriented, filtered analysis}

An important element of the newly modeled concept, of the assisting system, are mechanisms that allow for quick filtration of information and quick compilation of information depending on the contexts. It is equally important to search for the right form of a given activity, within a predefined set of forms.

\subsubsection{Tools for fast visualization of activities and their contexts}

The project assumes that work with the system should take place with a high level of search automation, appropriate for the problem being solved. In the absence of an existing, relevant instance of activity, helpful contextual information should be generated quickly, visualizing available, related instances of activity, their sources and examples of use in specific, previous projects.

\subsubsection{Pre-configured activity templates}

If a designer decides to create a new activity model, they are offered the option of using pre-configured activity templates - cf. Figure 3. For instance [30]: activity with substantial parallel extension, activity with hierarchical extension, etc. 


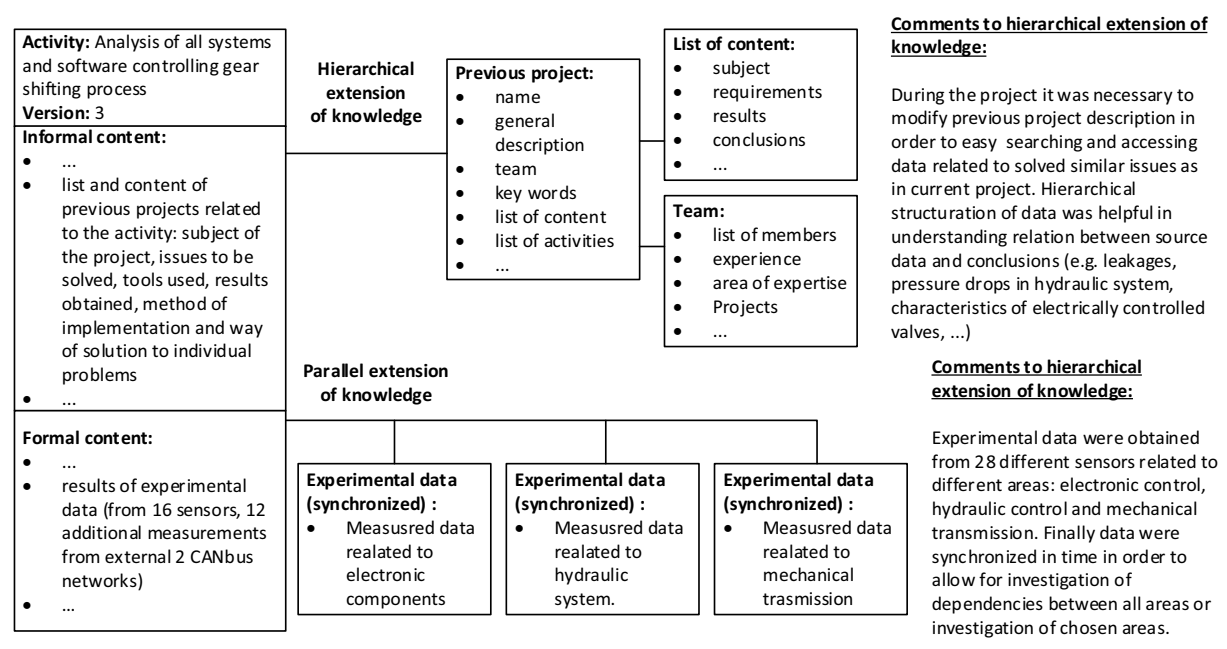

Figure 3. Example of activity template with parallel or hierarchical extension.

\subsubsection{Final comments}

All solutions developed to improve the process of creating advanced activity models depend very much on the data sets that are used at the time of testing.

The authors in their achievements relied on the documentation of an exemplary project task. The process of testing the concept consisted basically of analyzing different sets and subsets of information/knowledge elements and relationships between them. At that time this process was largely manual.

\section{Conclusions}

The authors, after completing the analyses presented in the work, attempted to create tools that allow to refer to specific functionalities, both their characteristics and resources, versions or applications.

The newly created functionalities will be tested on real-life examples of other CPS.

\section{References}

[1] C. Kan, C. J. Anumba, J. I. Messner, A Framework for CPS-Based Real-Time Mobile Crane Operations, In: I. Mutis and T. Hartmann (eds.), Advances in Informatics and Computing in Civil and Construction Engineering, Springer Nature Switzerland AG, 2019, pp. 653-660

[2] A. Darwish, A. E. Hassanien, Design, modelling, simulation and integration of cyber physical systems: Methods and applications, J Ambient Intell Human Comput (2018) 9, pp.1541-1556

[3] S. K. Khaitaan, J. D. McCalley. Design Techniques and Applications of Cyber Physical Systems: A Survey. IEEE Systems Journal, 2015, 9(2), pp. 350 - 365.

[4] C. Ptolemaeus, System Design, Modeling, and Simulation using Ptolemy II. Ptolemy.org., Los Angeles, 2014.

[5] A. Lee Edward, A. Seshia Sanjit, Introduction to Embedded Systems, A Cyber-Physical Systems Approach, Second Edition, MIT Press, ISBN 978-0-262-53381-2, 2017. 
[6] R. Chamberlain, W. Taha, M. Törngren Cyber Physical Systems. Model-Based Design - 2019 8th International Workshop, CyPhy 2018, and 14th International Workshop, WESE 2018, Turin, Italy, October 4-5, Springer International Publishing, Switzerland, 2018.

[7] P. Hehenberger, B. Vogel-Heuser, D. Bradley, B. Eynard, T. Tomiyama, S. Achiche. Design, modelling, simulation and integration of cyber physical systems: Methods and applications. Computers in Industry. Vol 82, 2016, pp 273-289.

[8] Q. Zhu and A. Sangiovanni-Vincentelli, Codesign Methodologies and Tools for Cyber-Physical Systems, in Proceedings of the IEEE, Sept. 2018, Vol. 106, no. 9, pp. 1484-1500, doi: 10.1109/JPROC.2018.2864271

[9] R. Alguliyev, Y. Imamverdiyev, L. Sukhosta. Cyber-physical systems and their security issues. Computers in Industry, Vol. 100, 2018, pp 212-223.

[10] S. Gupta, Yagnyasenee and Mukherjee, Shyamapada, A Survey on Security Issues in Cyber-Physical Systems (2018). International Journal of Computational Intelligence \& IoT, Vol. 1, No. 2, 2018. Available at SSRN: https://ssrn.com/abstract=3354499

[11] N.N., Special Publication 800-82 Rev 2. Guide to Industrial Control Systems (ICS) Security. Supervisory Control and Data Acquisition (SCADA) Systems, Distributed Control Systems (DCS), and Other Control System Configurations such as Programmable Logic Controllers (PLC), NIS National Institute of Standards and Technology, 2015.

[12] L. Knap, Design and Construction of the task-oriented Cyber-Physical System, The Institute for Sustainable Technologies - National Research Institute, 2017 (in Polish).

[13] J. Pokojski, L. Knap, M. Trojgo: Concept of an Assisting Tool in the Design and Development Process of a Product with the CPS - Case Study, Advances in Transdisciplinary Engineering, Vol. 10, 2019, pp. 95-104, red. DOI: 10.3233/ATDE190112

[14] J. Sobieszczanski-Sobieski, A. Morris and M. J.L. van Tooren, Multidisciplinary Design Optimization Supported by Knowledge Based Engineering, First Edition. John Wiley \& Sons, Hoboken, 2015.

[15] J. Stjepandic, N. Wognum, W.J.C. Verhagen, Concurrent Engineering in the 21st Century: Foundations, Developments and Challenges, Springer, Switzerland, 2015.

[16] S. André, F. Elgh, J. Johansson, R. Stolt, The design platform- a coherent platform description of heterogeneous design assets for suppliers of highly customized systems, Journal of Engineering Design, vol. 28, 2017, pp. 599-626.

[17] J. Pokojski, IPA (Intelligent Personal Assistant) - Concepts and Applications in Engineering, SpringerVerlag, London, 2004.

[18] D. Monticolo, J. Badin, S. Gomes, E. Bonjour, D. Chamoret, A meta-model for knowledge configuration management to support collaborative engineering, Computers in Industry, vol. 66, 2015, 11-20.

[19] S.K. Chandrasegaran, K. Ramani, R.D. Sriram, I. Horváth, A. Bernar, R. F. Harik, W. Ga, The evolution, challenges, and future of knowledge representation in product design systems, Computer-Aided Design, vol. 45, 2013, pp. 204-228.

[20] S.B. Shooter, V. B. Keiroz, S. Szykman and S.J. Fenves, A Model for The Flow of Design Information in Product Development, Engineering with Computers, Vol. 16, 2000, pp. 178-194.

[21] S. Szykman, R.D. Sriram, Ch. Bochenek, J.W. Racz and J. Senfaute, Design Repositories: Engineering Design's New Knowledge Base. IEEE Intelligent Systems, May/June, 2000, pp. 48-54.

[22] Y. Nomaguchi, K. Fujita, K., Knowledge representation framework for interactive capture and management of reflection process in product concepts development, Advanced Engineering Informatics, Vol. 27, 2013, pp. 537-554.

[23] S. Sim, A.H.B. Duffy, Towards an ontology of generic engineering design activities. Research Engineering Design, Vol. 14 , 2003, pp. 200-223.

[24] G. Pahl, W. Beitz, and al., Engineering Design: A Systematic Approach, Springer-Verlag, London, 2007.

[25] D.G. Ullman, The Mechanical Design Process, Third Edition, McGraw-Hill, New York, 2002.

[26] J. Pokojski, K. Oleksiński, J. Pruszyński, Knowledge based processes in the context of conceptual design, Journal of Industrial Information Integration, 2019, Vol. 15, pp. 219-238.

[27] J. Pokojski, K. Oleksiński, J. Pruszyński, Conceptual and Detailed Design Knowledge Management in Customized Production - Industrial Perspective, Journal of Computational Design and Engineering, Volume 6, Issue 4, October 2019, pp. 479-506.

[28] D. Baxter, J. Gao, K. Case, J. Harding, B. Young, S. Cochrane and S. Dani, An engineering design knowledge reuse methodology using process modelling, Research Engineering Design, Vol. 18, 2007, pp. 37-48.

[29] M. Stokes, Managing Engineering Knowledge, MOKA - project, Professional Engineering Publishing Limited, London, 2001.

[30] W.B. Arthur, The Nature of Technology, FREE PRESS, New York, 2009. 